\title{
Fetal Renal Volume and Renal Artery Doppler in Normal and Intrauterine Growth Restricted Fetuses
}

\author{
Hani Maged Abd El-Aal, Khaled Zakaria El-Sheikha and Ahmed Mohammed Abd-Elrazek \\ Ragab
}

\author{
Obstetrics and Gynecology Department, Faculty of Medicine, Al-Azhar University \\ Corresponding author: Ahmed M. Ragab; Mobile: 01066498927; Email: docahmedragab@ hotmail.com
}

\begin{abstract}
Objective: To evaluate the difference between fetal renal artery Doppler and fetal kidney volume in normal and intrauterine growth restricted fetuses

Design: A prospective cross sectional study.

Setting: Obstetrics and Gynecology department, Al-Azhar University.

Sample: One hundred pregnant women, 50 with normal fetal growth parameter, and 50 with restricted fetal growth.

Methods: Fetal renal volume was measured using 3-dimensional ultrasound. Umbilical artery and fetal renal artery Doppler indices were examined.

Main outcome measures: Correlation of Doppler parameter to fetal kidney volume, and association of fetal biometric indices to combined fetal kidney volume.

Results: Combined fetal renal volume was significantly reduced in growth restricted fetuses than in normally grown fetuses as the Mean of combined renal volume in IUGR was $(21.0 \pm 0.1)$ while in normal fetuses was $(31.24 \pm 2.31)$. All fetal biometric indices were positively associated with combined kidney volume. Concerning the umbilical artery Doppler and fetal renal artery Doppler there was significantly difference between the two groups as the intrauterine growth restricted fetuses have a high Doppler.

Conclusion: Intrauterine growth restriction appears to be associated with a statistically significant decrease in the renal volume than the normally growth fetuses. The renal artery Doppler shows also significant difference between the two groups, which matches with other studies. This study supports the hypothesis that intrauterine growth restriction may be linked to renal disease and hypertension in late life and renal volume can be used as a parameter for diagnosis of IUGR.
\end{abstract}

Keywords:Fetal kidney volume; fetal renal artery Doppler; Intrauterine growth restriction

\section{Introduction}

The human kidney develops through three successive embryonic stages. Transient development and regression of the primary (pronephros) and secondary (mesonephros) fetal kidneys occurs between day 23 and day 112. These primitive fetal kidneys have no impact on fetal renal function. The definitive, tertiary fetal kidney is the metanephros and this is the permanent functional kidney. It begins developing on day 30 leading to the formation of nephrons - the functional units within the kidney. Fetal kidneys are unlike most other organs in that the maximum cell proliferation occurs in the third trimester. Nephrogenesis continues up until 34-36 weeks gestation with approximately $60 \%$ of nephrons formed in the third trimester ${ }^{(\mathbf{1})}$.
Studies of kidney size in human fetuses of known gestational age have shown that intrauterine growth restriction is accompanied by decreased kidney volume compared to fetuses with appropriate weight for gestational age $^{(2)}$.

Fetuses that fail to meet their growth potential in utero are at risk for adverse antenatal and postnatal events such as stillbirth, preterm birth, and adverse neonatal and long-term health outcomes. Therefore, antenatal recognition and monitoring of intrauterine growth restriction (IUGR) is an important component of prenatal care. In its simplest form, IUGR is defined as a sonographic estimation of fetal weight below the tenth percentile for a given gestational age ${ }^{(3)}$.

Assessment of the fetal kidneys is an essential part of an obstetric ultrasound. Accurate 
information regarding kidney size is crucial to identifying kidney abnormalities and detecting changes in fetal kidney growth. Ultrasound imaging is safe, cost effective and widely available to evaluate fetal kidney size, echotexture and perfusion. A variety of two and three-dimensional ultrasound techniques have emerged and advanced to evaluate kidney development ${ }^{(\mathbf{1})}$.

Doppler ultrasound is a non-invasive useful tool to evaluate pregnancy outcome. This technique permits the examination of placental and fetal vessels providing information of fetoplacental health. Doppler ultrasound measures absolute velocities within an artery, from which resistance index (RI) is calculated. For this reason, in pregnant women, Doppler has become a routine technique for identifying fetal compromise associated with an abnormal uteroplacental or fetal circulation ${ }^{(4)}$.

\section{Methods}

This prospective, cross-sectional study was conducted from February 2017 to May 2018. All women attending the antenatal care clinic of Obstetrics and Gynecology Department, Sayed Galal Hospital, Faculty of Medicine, Al Azhar University, were invited to participate after taking an informed consent. Inclusion criterions were singleton pregnancy more than 34Weeks of gestation. Maternal Age 20-36 years and the patient must be sure of last menstrual period. Exclusion criteria include multiple pregnancy, uterine anomalies, fetuses with any congenital anomalies, structural anomalies both renal and non-renal, unclear renal margins and poorly visualized kidneys were excluded.
One hundred women were included, 50 were from uncomplicated pregnancies and 50 with intrauterine growth restriction (IUGR). The study was approved by the local hospital ethics committee.

Group A: including patients with intrauterine growth retardation (50females)

Group B: including patients with normal pregnancy (50 females)

Gestational age was based on the first day of the last normal menstrual period and confirmed by either first or early secondtrimester ultrasound scan. Fetal biometry including head circumference, abdominal circumference, and femur length and estimated fetal weight was measured.

Measurement of fetal renal volume done with VOCAL (Virtual Organ Computer Aided Analysis) method. Using three-dimensional US systems with VOCAL method gives a good agreement with true kidney volumes ${ }^{(5)}$.

Fetal renal Doppler was done by using color Doppler

\section{Data analysis}

All statistical analyses were performed using the Statistical Package of Social Sciences version 20.0 for Windows (SPSS Inc., Chicago, IL, USA).

\section{Results}

The mean gestational age by date in IUGR group \pm SD was $36.72 \pm 1.53$ weeks and for normal group was $37.74 \pm 1.41$ with no difference between the two groups but the mean gestational age by ultrasound was in IUGR $32.5 \pm 2.02$ and in the normal group was $36.72 \pm 1.40$.

Table (1): Comparison between both groups as regards gestational age

\begin{tabular}{|c|c|c|c|c|c|c|c|}
\hline \multicolumn{2}{|l|}{ Gestational age } & \multicolumn{3}{|c|}{ Range } & \multirow{2}{*}{$\begin{array}{l}\text { Mean } \\
36.72\end{array}$} & \multirow{2}{*}{$\begin{array}{l} \pm \text { S. D } \\
\pm 1.53\end{array}$} & \multirow{3}{*}{$\begin{array}{l}\text { p. value } \\
0.812\end{array}$} \\
\hline \multirow{2}{*}{ G. age by date } & Group A & 35 & - & 39 & & & \\
\hline & Group B & 34.5 & - & 39 & 36.79 & \pm 1.41 & \\
\hline \multirow{2}{*}{ G. age by US } & Group A & 28 & - & 35.2 & 32.50 & \pm 2.02 & \multirow{2}{*}{$0.001 *$} \\
\hline & Group B & 34.5 & - & 39 & 36.79 & \pm 1.40 & \\
\hline
\end{tabular}


Table (2): Comparison between both group as Right, Left and combined renal volumes. Our study showed that there is significant difference between renal volumes in both groups as the IUGR has smaller kidney than normal group

\begin{tabular}{|c|c|c|c|c|c|c|c|}
\hline \multicolumn{2}{|c|}{ Renal volume } & \multicolumn{3}{|c|}{ Range } & \multirow{2}{*}{$\frac{\text { Mean }}{10.35}$} & \multirow{2}{*}{$\begin{array}{l} \pm \text { S. D } \\
\pm 0.58\end{array}$} & \multirow{3}{*}{ p. value } \\
\hline \multirow{2}{*}{ Right } & \begin{tabular}{|l|} 
Group A \\
\end{tabular} & 9.3 & - & 11.2 & & & \\
\hline & Group B & 12.9 & - & 18.40 & 15.44 & \pm 1.76 & \\
\hline \multirow{2}{*}{ Left } & Group A & 9.4 & - & 11.6 & 10.65 & \pm 0.62 & \multirow{2}{*}{$0.001^{*}$} \\
\hline & Group B & 13.3 & - & 18.7 & 15.80 & \pm 1.62 & \\
\hline \multirow{2}{*}{ Combined } & Group A & 18.9 & - & 22.4 & 21.0 & \pm 1.0 & \multirow{2}{*}{$0.001 *$} \\
\hline & Group B & 26.7 & - & 36 & 31.24 & \pm 2.31 & \\
\hline
\end{tabular}

Table (3): shows that there's significant difference in the measurements of renal artery Doppler between the two groups.

\begin{tabular}{|c|c|c|c|c|c|c|c|}
\hline \multicolumn{2}{|l|}{ Renal artery Doppler } & \multicolumn{3}{|c|}{ Range } & \multirow{2}{*}{$\begin{array}{l}\text { Mean } \\
0.94\end{array}$} & \multirow{2}{*}{$\begin{array}{ll} \pm & \text { S. D } \\
\pm 0.02 \\
\end{array}$} & \multirow{3}{*}{$\begin{array}{l}\text { p. value } \\
0.001^{*}\end{array}$} \\
\hline \multirow{2}{*}{ RA Resistive index } & Group A & 0.89 & $\begin{array}{l}- \\
\end{array}$ & 0.98 & & & \\
\hline & Group B & 0.7 & - & 0.86 & 0.79 & \pm 0.04 & \\
\hline \multirow{2}{*}{ RA Pulsatile index } & Group A & 1.76 & - & 2.01 & 1.90 & \pm 0.08 & \multirow{2}{*}{$0.001 *$} \\
\hline & Group B & 1.3 & - & 1.6 & 1.49 & \pm 0.07 & \\
\hline
\end{tabular}

Table (4): shows that there's significant difference in Doppler study of umbilical artery between the two groups.

\begin{tabular}{|c|c|c|c|c|c|c|c|}
\hline \multicolumn{2}{|c|}{ Umbilical artery Doppler } & \multicolumn{3}{|c|}{ Range } & \multirow{2}{*}{$\begin{array}{l}\text { Mean } \\
0.87 \\
\end{array}$} & \multirow{2}{*}{$\begin{array}{l} \pm \text { S. D } \\
\pm 0.01\end{array}$} & \multirow{3}{*}{$\frac{\text { p. value }}{20.001^{*}}$} \\
\hline \multirow{2}{*}{ UA RI } & Group A & 0.75 & - & 0.98 & & & \\
\hline & Group B & 0.58 & - & 0.6 & 0.59 & \pm 0.01 & \\
\hline \multirow{2}{*}{ UA PI } & Group A & 1.41 & - & 1.95 & 1.74 & \pm 0.14 & \multirow{2}{*}{$0.001^{*}$} \\
\hline & Group B & 0.73 & - & 0.89 & 0.80 & \pm 0.144 & \\
\hline
\end{tabular}

\section{Discussion}

Fetal growth is a result of complex interactions between the genetic growth potential of the fetus and the impact of the maternal intrauterine environment. Causes of intrauterine growth restriction (IUGR) are generally classified as maternal, fetal, or placental. However, such distinction is rather theoretical, as these factors often overlap each other. IUGR is diagnosed when ultrasoundestimated fetal weight is below the $10^{\text {th }}$ percentile for gestational age. A diagnosis of IUGR implies a pathologic growth restriction responsible for low fetal weight ${ }^{(6)}$.

Extensive circulatory changes occur in fetuses with IUGR caused by placental insufficiency. These changes which are called redistribution or (brain-sparing) effect result in a reduction in the peripheral vascular resistance and accordingly, increased blood flow in organs which are essential for survival (e.g. brain and heart) and decreased blood flow in other parts (e.g. limbs, liver and kidneys) ${ }^{(7)}$.

The aim of our study was to compare the fetal kidneys volume between normal fetuses and
IUGR fetuses. We also aimed to compare fetal renal artery Doppler in the same groups.

Since the most common definition used for IUGR is fetal weight below the $10^{\text {th }}$ percentile for gestational age; we tried to take in our consideration this definition in choosing our cases, so all IUGR cases had $\mathrm{EFW}<10$ percentile.

In our study concerning the maternal age, there was no statistically significant difference between the two groups as the mean maternal age in cases was $(26.94 \pm 3.27$ years) and in control group was ( $26.30 \pm 3.47$ years); $\mathrm{P}$ value $=0.345$. and both groups were matched for number of parity and the result revealed that there is no significant deference between both groups as the number of parity in cases was (1.86 \pm 1.34 times) and in control group was $(1.76 \pm 1.33$ times $) ; \mathrm{P}$ value $=0.709$.

Our study showed that, although the two groups were very nearby in their GA by date of last menstrual period as the mean gestational age by date in cases was $(36.72 \pm$ 


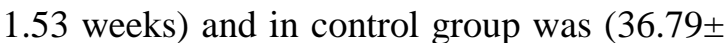
1.41 weeks) there was significant difference between the two groups as regard gestational age by ultrasound as the mean gestational age by scan in cases was ( $32.5 \pm 2.02$ weeks) and control group was $(36.79 \pm 1.40$ weeks $)$.

Although the two groups of our study were very close in their GA and, their biometric measurements were significantly lower in IUGR group.

In 2008, there was a study in the Comparison of Fetal and Neonatal Growth Curves in Detecting Growth Restriction and showed that (All body size measurements were significantly higher in AGA than in IUGR) ${ }^{(8)}$.

Concerning the umbilical artery Doppler and fetal renal artery Doppler there was significant difference between the two groups as the mean of resistive index of umbilical artery of IUGR cases was $(0.87 \pm 0.01)$ and for control group was $(0.59$ $\pm 0.01)$ and the mean of umbilical artery pulsatile index in IUGR cases was (1.74 $\pm 0.14)$ and in control group was $(0.80 \pm 0.144)$.

As regard renal artery resistive index in IUGR cases was $(0.94 \pm 0.02)$ and in control group was $(0.79 \pm 0.004)$ and renal artery PI in IUGR was $(1.90 \pm 0.08)$ and in normal fetuses was $(1.49 \pm 0.07)$

Our results meet with a previous study, which revealed that there was significantly difference was seen between the Doppler parameters of renal artery in normal and growth restricted fetuses. AS compared to the normal fetuses, the renal artery in growth retarded fetuses showed slightly decreased systolic velocities with increase in the pulsatility index ${ }^{(9)}$.

In our study concerning renal volume we found that there was significant difference between the two groups as the IUGR cases had smaller renal volume than normal group. The mean of the right renal volume in IUGR group was $(10.35 \pm 0.58)$ and in control group was $(15.44 \pm 1.76)$ with significant $p$ value $<0.05$, in the left side the renal volume in IUGR group was $(10.65 \pm 0.65)$ and in normal group was $(15.80 \pm 1.62)$ with significant $p$ value $<0.05$.

\section{Conclusion:}

- The advantage of 3-D U/S in assessing fetal renal volume is that the dataset can be stored at the time of examination and analyzed later to calculate volume. Also this dataset can be manipulated later to view the kidney in the coronal and sagittal planes, in addition to the transverse plane in which the sweep was obtained.

- Fetal renal volume and renal artery Doppler are affected significantly with IUGR and it can be used as a parameters for diagnosis of IUGR.

\section{Reference}

1. Sonja B, David W, Donna $\mathrm{R}$ et al. (2017): Evaluation of fetal kidney growth using ultrasound: A systematic review. European Journal of Radiology, 96:55-64.

2. Verburg BO, Geelhoed JJ, Steegers EA, Hofman A, Moll HA et al. (2007): Fetal kidney volume and its association with growth and blood flow in fetal life: The Generation R Study. Kidney Int., 72: 754761.

3. Easter SR, Eckert LO, Boghossian N, Spencer R, Oteng-Ntim E, Ioannou $\mathrm{C}$ et al.(2017): The brighton collaboration fetal growth restriction working group. fetal growth restriction: case definition \& guidelines for data collection, analysis, and presentation of immunization safety data. Vaccine, 35 : 6546-6554

4. Everett TR, Lees CC (2012). Beyond the placental bed: Placental and systemic determinants of the uterine artery Doppler waveform. Placenta, 33(11): 893-901.

5. Yoshizaki CT, Francisco RPV, De Pinho JC, Ruano R, \& Zugaib M (2013): Renal Volumes Measured by 3-Dimensional Sonography in Healthy Fetuses From 20 to 40 Weeks. Journal of Ultrasound in Medicine, 32(3): 421-427.

6. Gutaj $\mathbf{P} \&$ Wender-Ozegowska $\mathbf{E}$ (2016): Diagnosis and Management of IUGR in Pregnancy Complicated by Type 1 Diabetes Mellitus. Current Diabetes Reports, 16(5): 1531-1547.

7. Giussani DA (2016): The Fetal Brain Sparing Response to Hypoxia: Physiological Mechanisms. The Journal of Physiology, 594:1215-1230. 
Fetal Renal Volume and Renal Artery Doppler in Normal and Intrauterine Growth....

8. Marconi AM, Ronzoni S, Bozzetti P, Vailati S, Morabito A, Battaglia FC (2008): Comparison of Fetal and Neonatal Growth Curves in Detecting Growth Restriction. Obstetrics \& Gynecology, 112(6):1227-1234
9. Ratnaparkhi C, Kurve S, Mitra K, Onkar P, Kulkarni A, Kant D (2015):Correlation between Fetal Renal Volume and Fetal Renal Doppler in Normal and Growth Restricted Fetuses: An Initial Experience. Journal of Evolution of Medical and Dental Sciences, 4(63): 10956-10966 